Institute of $\mathbf{F}_{\text {ood and }} \mathbf{A}_{\text {gricultural }} \mathbf{S}_{\text {ciences }}$

\title{
Residential Irrigation System Rainfall Shutoff Devices ${ }^{1}$
}

\section{Michael D. Dukes and Dorota Z. Haman ${ }^{2}$}

Rain sensors -- also called rain shut-off devices -are designed to interrupt the cycle of an automatic irrigation system controller when a specific amount of rainfall has occurred. They are small devices wired to the irrigation system controller and mounted in an open area where they are exposed to rainfall.

Some of the new irrigation controllers have a special connection which allows a rain sensor to be attached directly. If such a shut-off device is not available, or the sensor doesn't work with a given controller, the sensor can always be "hard-wired" into the controller. This is done by wiring the rain sensor in series with the common wire. When a specific amount of rainfall has occurred, the rain sensor will interrupt the system's common wire, which disables the solenoid valves until the sensor dries.

Florida is the only state in the nation with an overall rain sensor statute. Beginning in 1991, this statute applies to all new automatic sprinkler systems: "Any person who purchases and installs an automatic lawn sprinkler system after May 1, 1991, shall install, and must maintain and operate, a rain sensor device or switch that will override the irrigation cycle of the sprinkler system when adequate rainfall has occurred" (Florida Statute 373.662). Some Florida counties and communities have passed laws stating that all automatic landscape irrigation systems require rain sensors, regardless of age. Rain sensors are available wherever irrigation supplies are sold, and a homeowner or irrigation professional can install them.

Advantages of a rain sensor:

- Conserves water -- prevents irrigation after recent rain events.

- Saves money -- reduces utility bills by interrupting the irrigation system after adequate rainfall.

- Reduces wear on the irrigation system because the system runs only when necessary.

- Reduces disease damage by eliminating unnecessary irrigation events.

- Helps protect surface and groundwater by reducing the runoff and deep percolation that carries pollutants, such as fertilizers, into storm drains and groundwater.

\section{Types of Devices}

Rain sensors operate by one of two methods. 1) Shut-off devices may either measure or weigh collected rainwater. Devices that collect water

1. This document is ABE325,one of a series of the Agricultural and Biological Engineering Department, Florida Cooperative Extension Service, Institute of Food and Agricultural Sciences, University of Florida. First published July 2002. Please visit the EDIS Web site at http://edis.ifas.ufl.edu.

2. Michael D. Dukes, assistant professor; Dorota Z. Haman, professor; Agricultural and Biological Engineering Department, Institute of Food and Agricultural Sciences, University of Florida, Gainesville.

The Institute of Food and Agricultural Sciences is an equal opportunity/affirmative action employer authorized to provide research, educational information and other services only to individuals and institutions that function without regard to race, color, sex, age, handicap, or national origin. For information on obtaining other extension publications, contact your county Cooperative Extension Service office. Florida Cooperative Extension Service/Institute of Food and Agricultural Sciences/University of Florida/Christine Taylor Waddill, Dean. 
operate on two basic principles: water weight; or electrical conductivity of water. 2) Shut-off devices may measure proportional expansion of water-senstitive materials, such as cork disks.

Water weight -- When a preset weight of water is collected in a small dish, the connection to the automatic irrigation valve is interrupted until the dish is emptied or a portion of water evaporates reducing the weight below the critical level. A disadvantage of this device is that any other weight (debris, frogs, etc.) can turn off the irrigation system and it requires more maintenance (Figure 1).

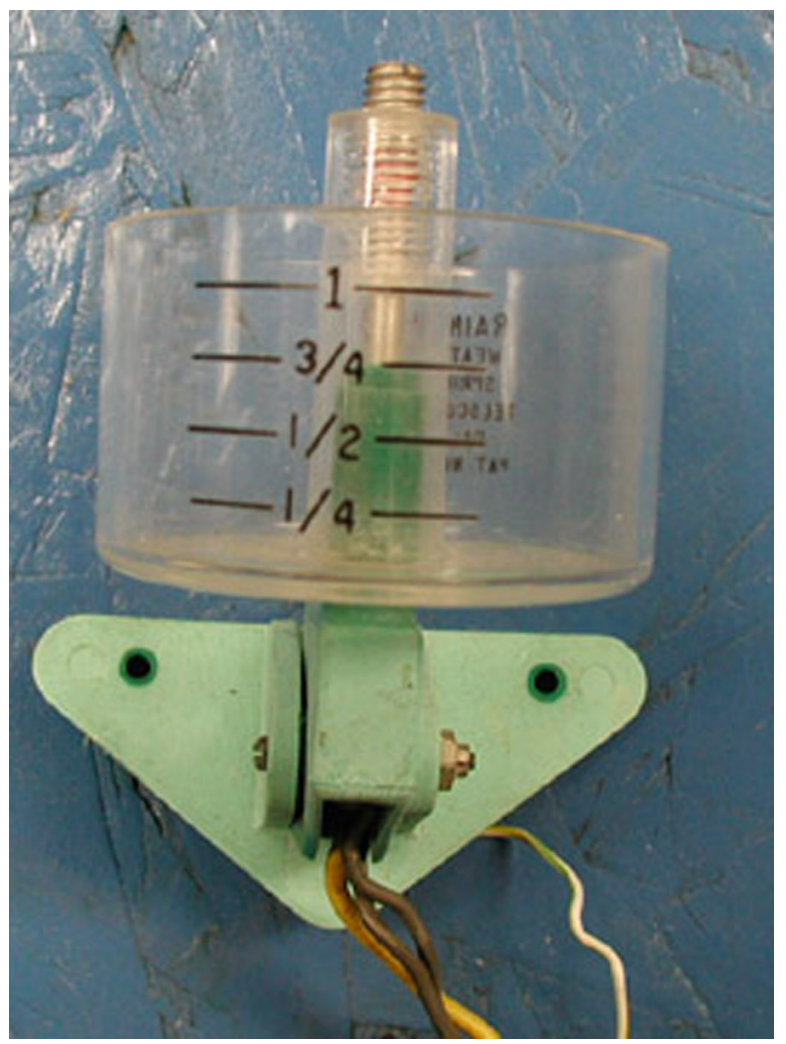

Figure 1. Weight-based rain shut-off device.

Electrical conductivity of water -- A set of electrodes is used to detect the water level in a small collection dish. The distance between the bottom of the collection dish and the electrodes can be adjusted so the irrigation system is not switched off by small rain events. Typically, the sensor is set to detect rain events larger that $1 / 2$ inch. Similar to the previous type, water may have to be removed from the dish, and debris may create some problems (Figure 2).

Expansion disks -- This device is the most popular rain sensor due to high reliability and low

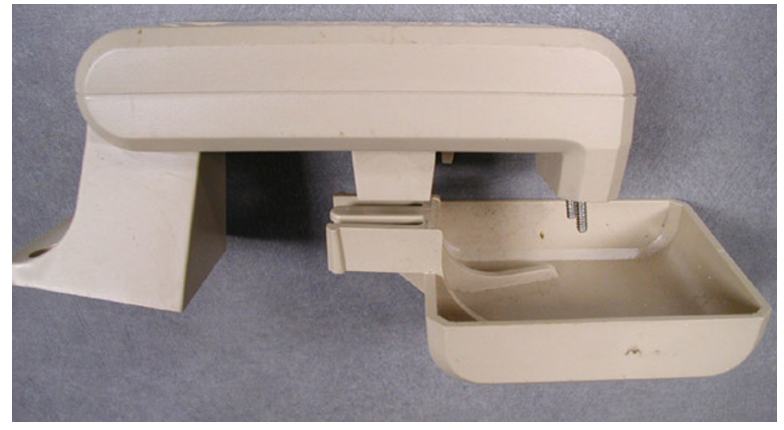

Figure 2. Rain shut-off device based on electrical conductivity.

maintenance. Expanding cork disks trigger a pressure switch. The expansion space can be easily adjusted by rotation of the disk cover to a predetermined amount of rain required to trigger the switch. The amount of rain that will interrupt the irrigation system is marked on the adjustment cap (Figure 3 and Figure 4).

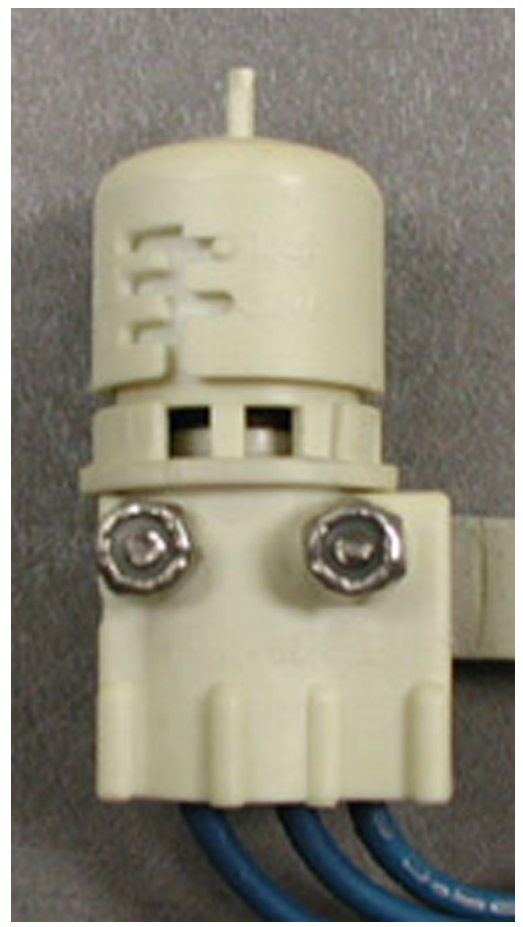

Figure 3. Rain shut-off device with expanding material.

\section{Installing the Device}

A rain sensor should be mounted where it will be exposed to unobstructed rainfall, but not in the path of sprinkler spray. It is typically installed near the roofline on the side of a building. However, it should not be mounted such that it comes into contact with water running directly off the roof. If vandalism is not a threat, it can be mounted lower on a fence post or 


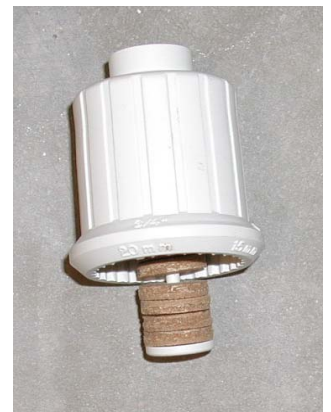

Figure 4. The expanding material of a shut-off device is visible in this photo of the cap removed from a device similar to the one in figure 3.

deck railing. It is important that trees, overhangs, and awnings are not blocking direct rainfall onto the device.

The closer the sensor is to the controller, the shorter the wire and less chance for wire breaks. Mounting the sensor in a very sunny, southern end of a building may cause the water to dry out sooner than desired. Conversely, mounting on the northern end of a building with constant shade may keep it from drying soon enough, especially in Florida's humid climate. Some experimentation with adjustment of sensor level is strongly recommended for best results.

The controllers that are provided with a plug for a rain sensor require that the sensor be compatible with a given type of controller. The sensor can operate as "normally closed" or "normally open."

If a given sensor does not work with a controller that is already installed, it can always be "hard-wired" into the controller. If the sensor is purchased at the time of controller installation, it is a good idea to check for compatibility of both devices.

\section{Testing}

The device can be tested during normal rainfall events by setting out several containers with dimensions similar to those recommended for testing irrigation system uniformity (see How to Calibrate Your Sprinkler System). At least three containers should be located in the yard such that rainfall can accumulate freely in these containers. Measure the depth of water in each container with a ruler, and calculate the average of the measurements. When the containers average $1 / 2$ inch of rainfall, set the rainfall sensor to $1 / 2$ inch and manually initiate the irrigation system at the controller. The system should not operate. If this is the case, the rainfall sensor is adjusted properly. If the system runs, the rainfall sensor may have to be: 1) cleaned, 2) located so that rainfall will contact it, or 3) repaired or replaced. Sensors with electrodes (see Figure 2) may require cleaning of the electrodes and/or cleaning of the catch container. Sensors with a weighing dish or cup (see Figure 1) may require periodic cleaning of the container.

\section{Potential Water and Cost Savings}

The amount of water that can be saved using rain shut-off devices varies, but in a year with average rainfall, savings are usually substantial. There are several factors involved in determining how much a sensor can reduce water usage: how often it rains, whether or not the controller is left on for automatic operation, and the amount of water applied by the system per cycle. If the water costs and the amount of water applied per watering cycle by the whole system are known, it is easy to calculate how much money is being saved each time the sensor interrupts the watering cycle because of rainfall.

As an example, if a system irrigates $1 / 2$ acre of turf and is set to run each zone so that $1 / 2$ inch of water is applied per cycle, one can calculate that 13,576 gallons are being applied over the $1 / 2$ acre of turf per cycle. Assuming water costs $\$ 2.00 /$ thousand gallons, the savings will be $\$ 27.15$ every time the sensor eliminates an irrigation event. What is even more important, 13,576 gallons that would be lost to deep percolation or runoff will be saved. If this amount is multiplied by the number of substantial rainfalls that occur in the area over one growing season, a significant amount of money and water can be saved.

\section{References}

How to Calibrate Your Sprinkler System (IFAS Publication ENH-61) (On the Web at: http://edis.ifas.ufl.edu/LH026) 